\title{
Natural and Semisynthetic Chalcones as Dual FLT3 and Microtubule Polymerization Inhibitors
}

Haleema Sadia Malik, Aishah Bilal, Rahim Ullah, Maheen Iqbal, Sardraz Khan, Ishtiaq Ahmed, Karsten Krohn, Rahman Shah Zaib Saleem, Hidayat Hussain, and Amir Faisal

\section{Supplementary Information}

\section{Contents}

Page S2: Figure S1. Differential screening of chalcone derivatives in AML and CML cell lines Page S3: Figure S2. Inhibition of FLT3 signaling by chalcone derivatives in MV-4-11 cell line Page S4: Figure S3. Inhibition FLT3 by chalcone $2(A)$ and chalcone $1(B)$ in a kinase assay Page S5: Figure S4. ${ }^{1} \mathrm{H}$ NMR spectrum of 2'-hydroxychalcone (1) $\left(500 \mathrm{MHz}, \mathrm{CDCl}_{3}\right)$.

Page S5: Figure S5. ESIMS spectrum of 2'-hydroxychalcone (1).

Page S6: Figure S6. ${ }^{1} \mathrm{H}$ NMR spectrum of 3,4,4'-trimethoxy-2'-hydroxychalcone (2) (500 MHz, $\left.\mathrm{CDCl}_{3}\right)$.

Page S6: Figure S7. ESIMS spectrum of 3,4,4'-trimethoxy-2'-hydroxychalcone (2) (500 MHz, $\mathrm{CDCl}_{3}$ ).

Page S7: Figure S8. ${ }^{1} \mathrm{H}$ NMR spectrum of 4,4'-dimethoxy-2'-hydroxychalcone (3) $500 \mathrm{MHz}$, $\mathrm{CDCl}_{3}$ ).

Page S7: Figure S9. ESIMS spectrum of 4,4'-dimethoxy-2'-hydroxychalcone (3).

Page S8: Figure S10. ${ }^{1} \mathrm{H}$ NMR spectrum of 2'-allyloxy-4,4'-dimethoxychalcone (4) $400 \mathrm{MHz}$, $\left.\mathrm{CDCl}_{3}\right)$.

Page S8: Figure S11. ${ }^{13} \mathrm{C}$ NMR spectrum of 2'-allyloxy-4,4'-dimethoxychalcone (4) $400 \mathrm{MHz}$, $\left.\mathrm{CDCl}_{3}\right)$.

Page S9: Figure S12. HRESIMS spectrum of 2'-allyloxy-4,4'-dimethoxychalcone (4). 


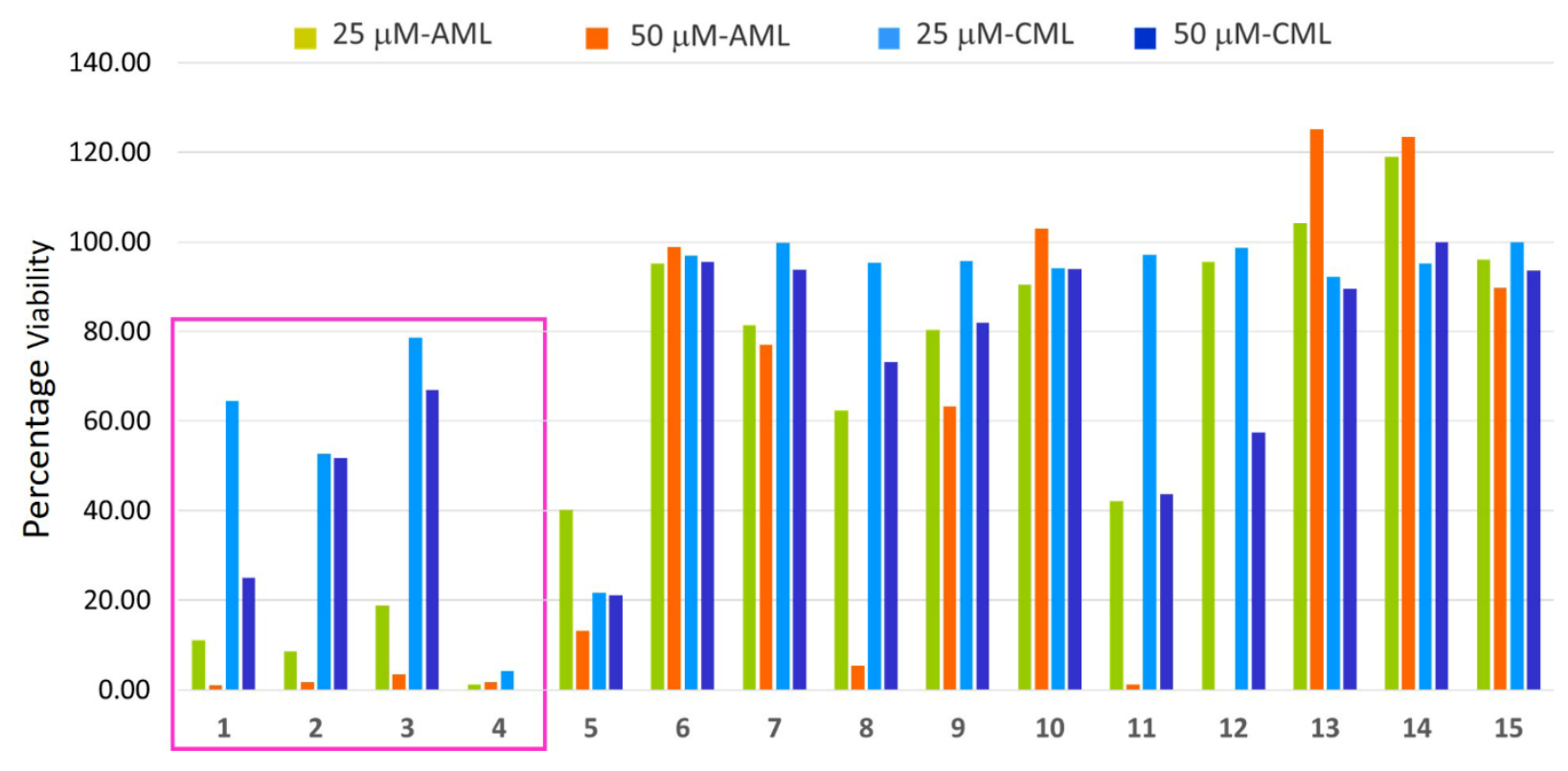

Figure S1. Chalcone derivatives are preferentially more potent for the AML cell line (MV-4-11) compared to CML cell line (K562). Percentage viability of MV-4-11 and K526 cell lines treated with $25 \mu \mathrm{M}$ and $50 \mu \mathrm{M}$ concentration of 15 chalcones in three-day MTS proliferation assays. Compounds relatively more potent in MV-4-11 are outlined in pink. 
A

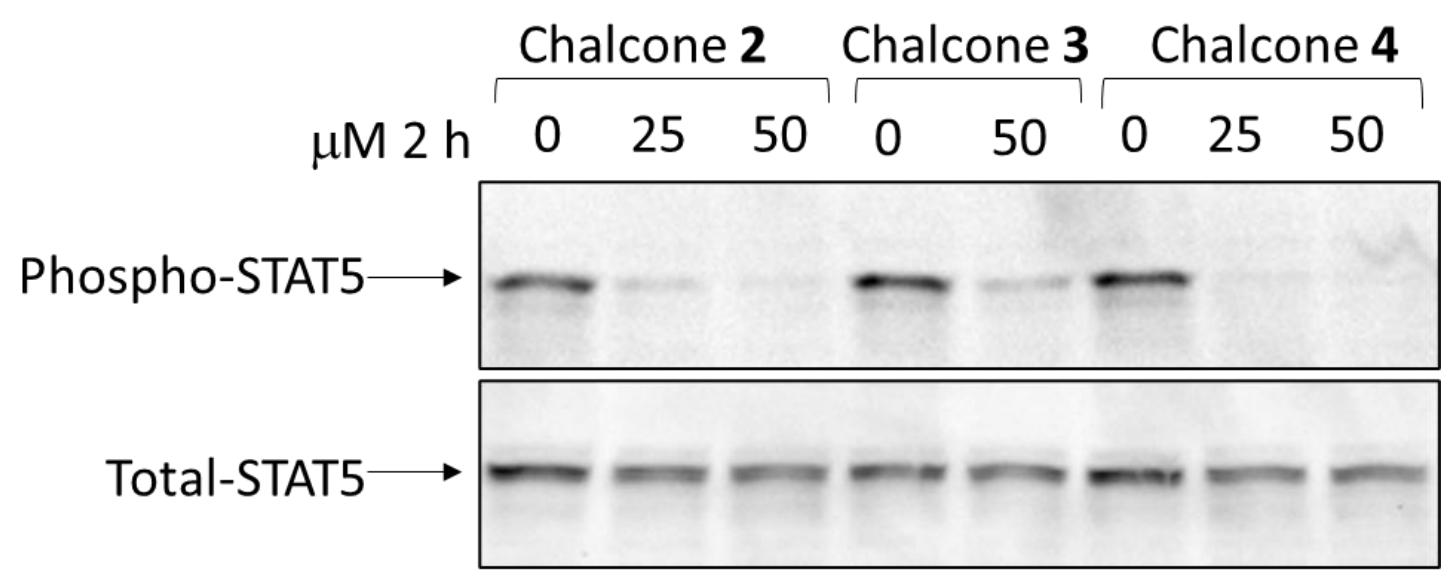

B

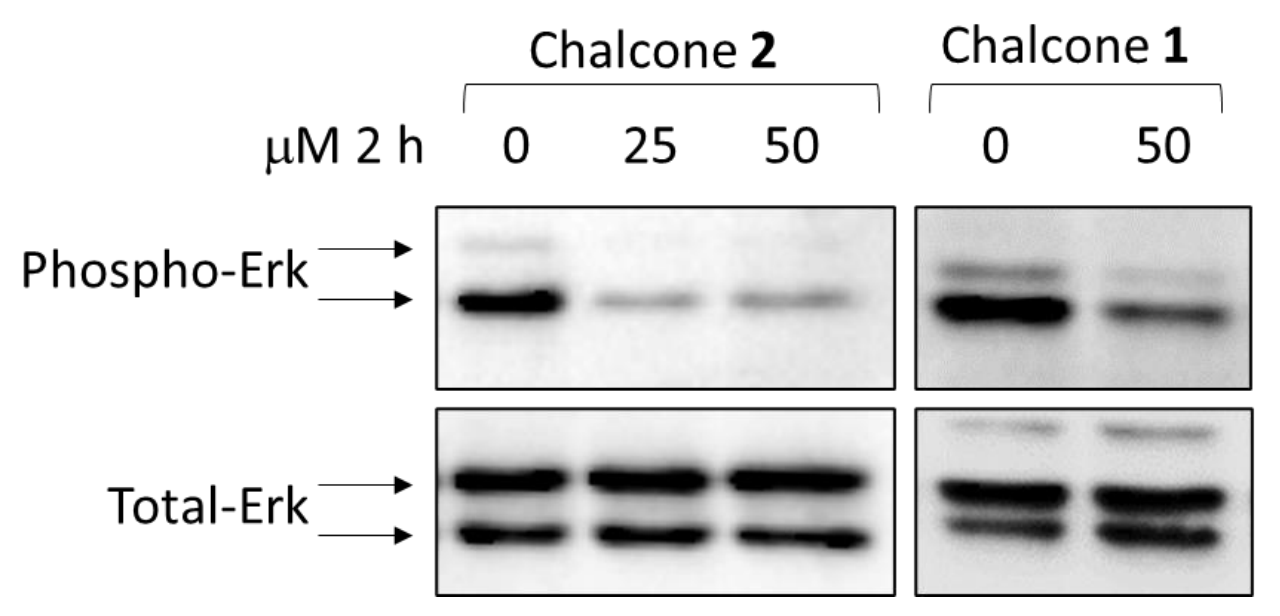

Figure S2. Inhibition of FLT3 signaling by chalcone derivatives in MV-4-11 cell line. A. Cells were treated with different concentrations of chalcones 2, 3 and 4 for 2 h and analyzed for Stat5 phosphorylation through immunoblotting using specific antibodies. Blotting with total Stat5 was used as a loading control B. Cells were treated with different concentrations of chalcones $\mathbf{1}$ and $\mathbf{2}$ for $2 \mathrm{~h}$ and analyzed for ERK phosphorylation through immunoblotting using specific antibodies. Blotting with total Erk was used as a loading control. 

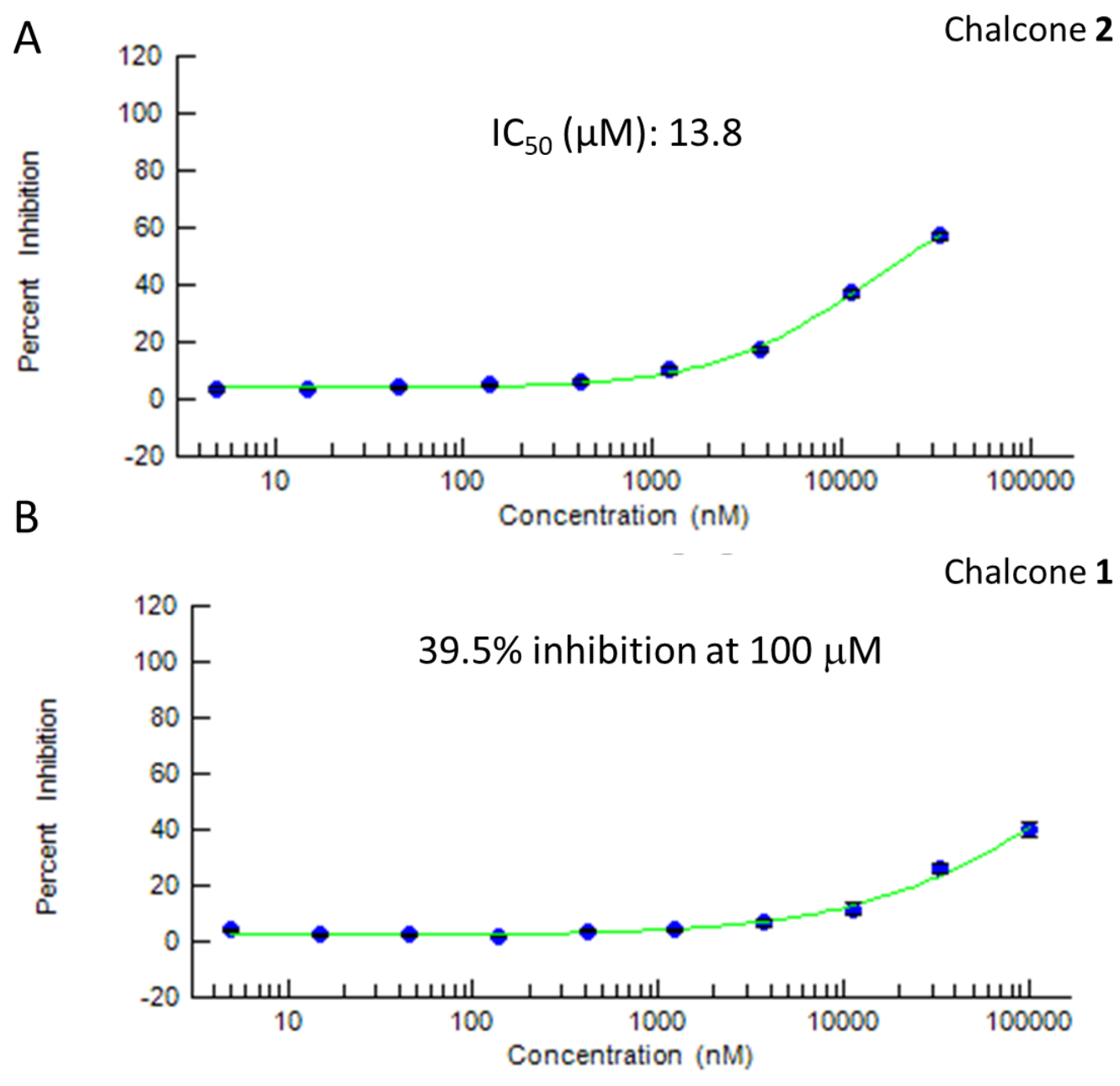

Figure S3. Inhibition of FLT3 by chalcone 2 (A) and chalcone 1 (B) in a kinase assay. 


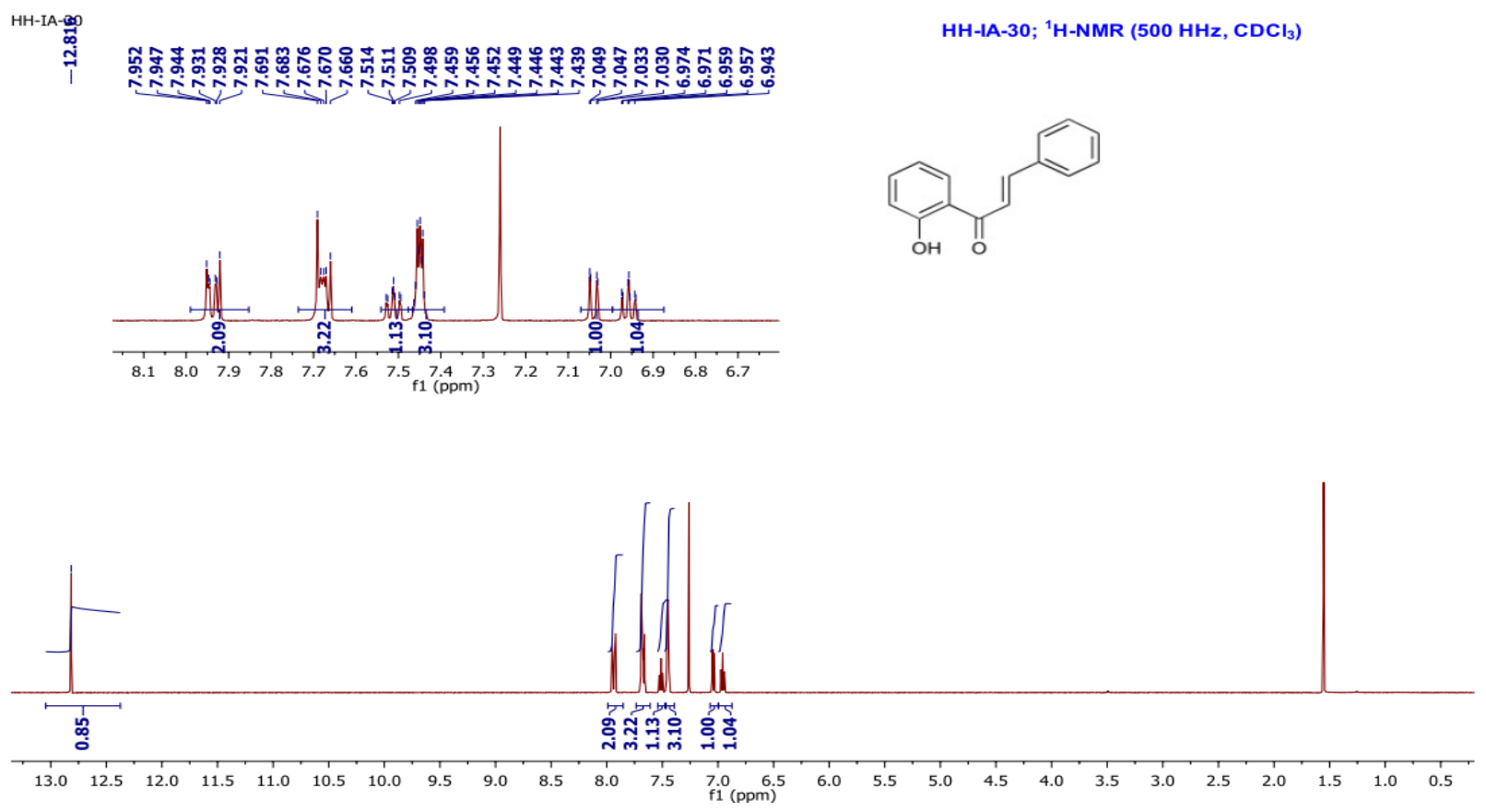

Figure S4: ${ }^{1} \mathrm{H}$ NMR spectrum of 2'-hydroxychalcone (1) $\left(500 \mathrm{MHz}, \mathrm{CDCl}_{3}\right)$.

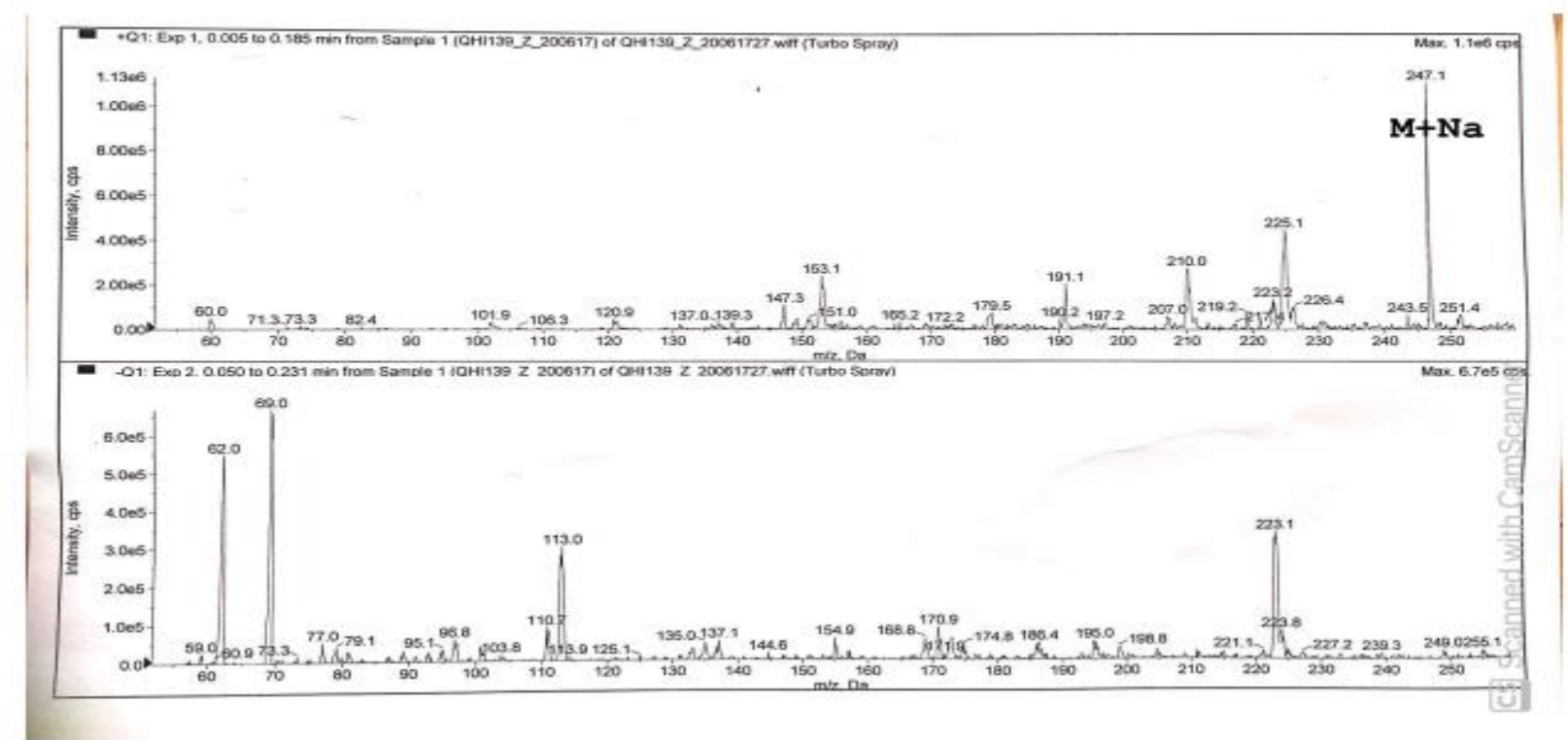

Figure S5: ESIMS spectrum of 2'-hydroxychalcone (1). 


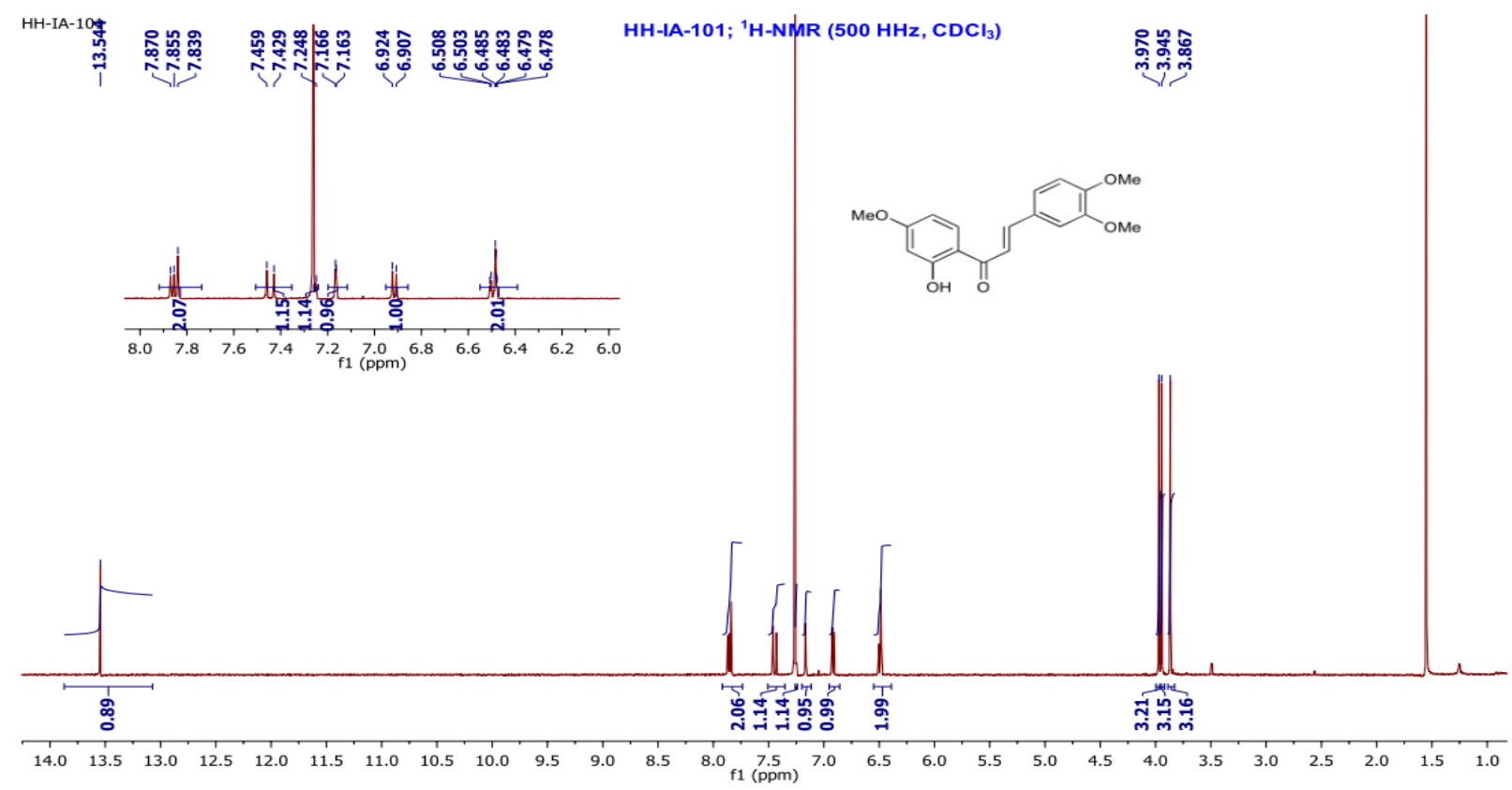

Figure S6: ${ }^{1} \mathrm{H}$ NMR spectrum of 3,4,4'-trimethoxy-2'-hydroxychalcone (2) (500 MHz, $\mathrm{CDCl}_{3}$ ).

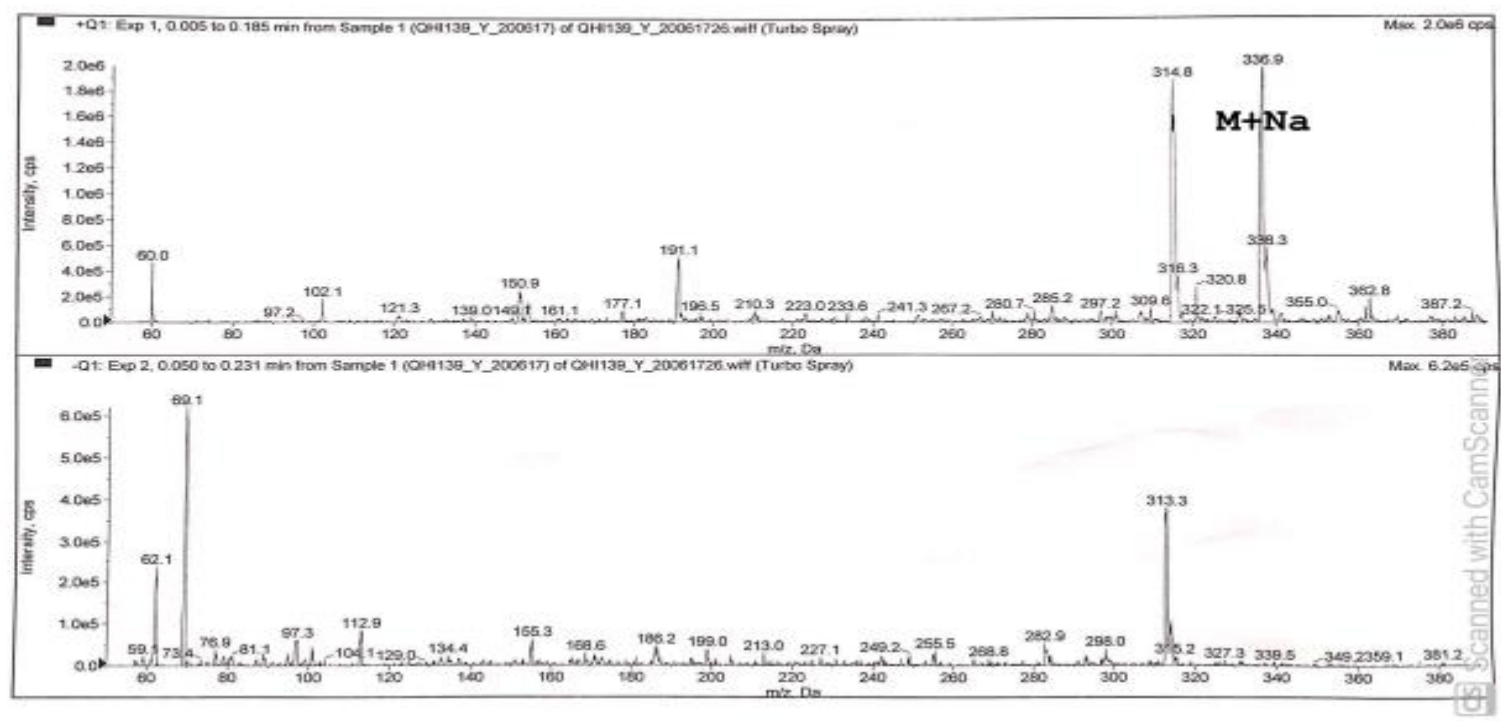

Figure S7: ESIMS spectrum of 3,4,4'-trimethoxy-2'-hydroxychalcone (2) (500 $\left.\mathrm{MHz}, \mathrm{CDCl}_{3}\right)$. 


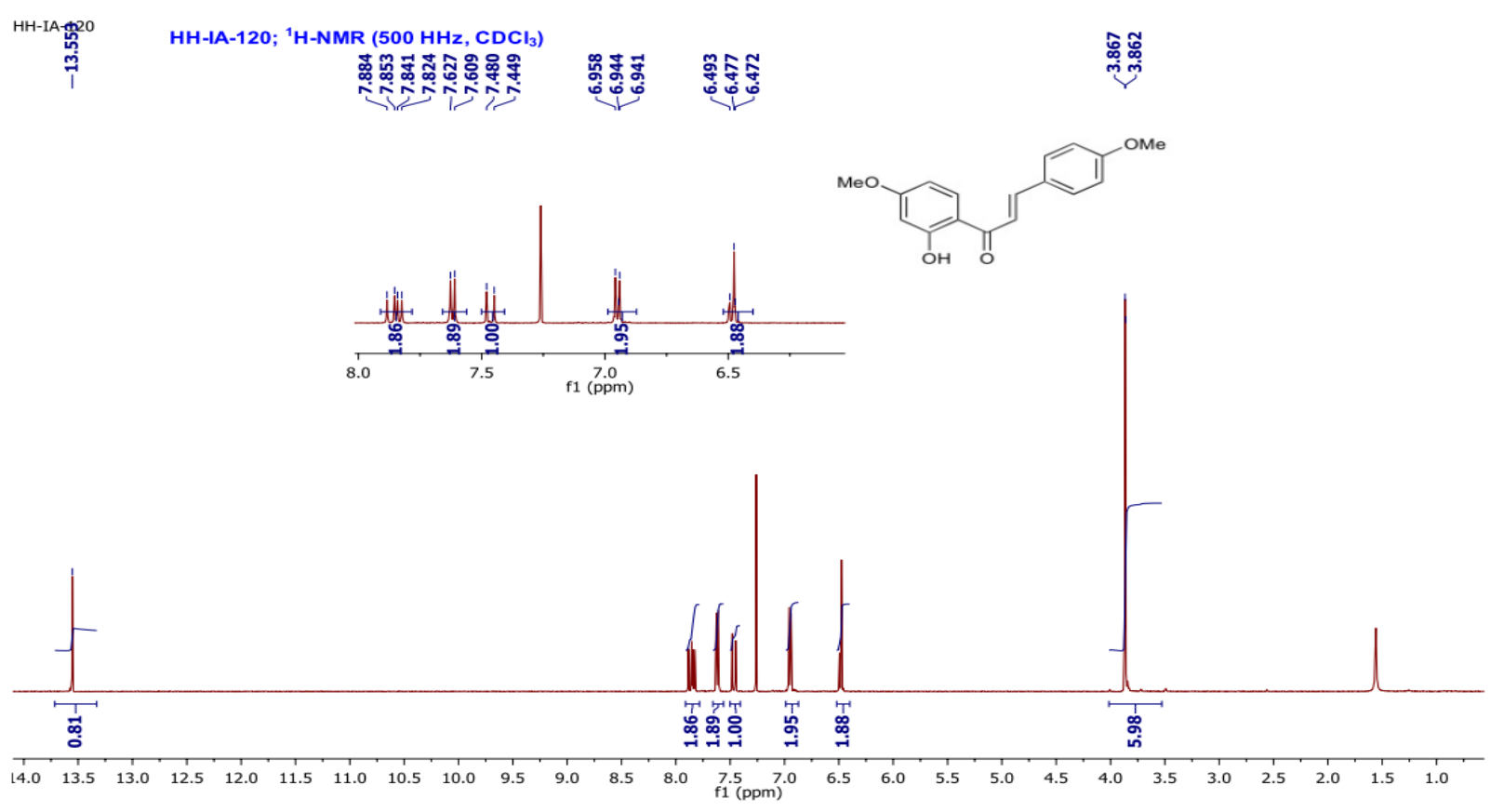

Figure S8: ${ }^{1} \mathrm{H}$ NMR spectrum of 4,4'-dimethoxy-2'-hydroxychalcone (3) $500 \mathrm{MHz}, \mathrm{CDCl}_{3}$ ).

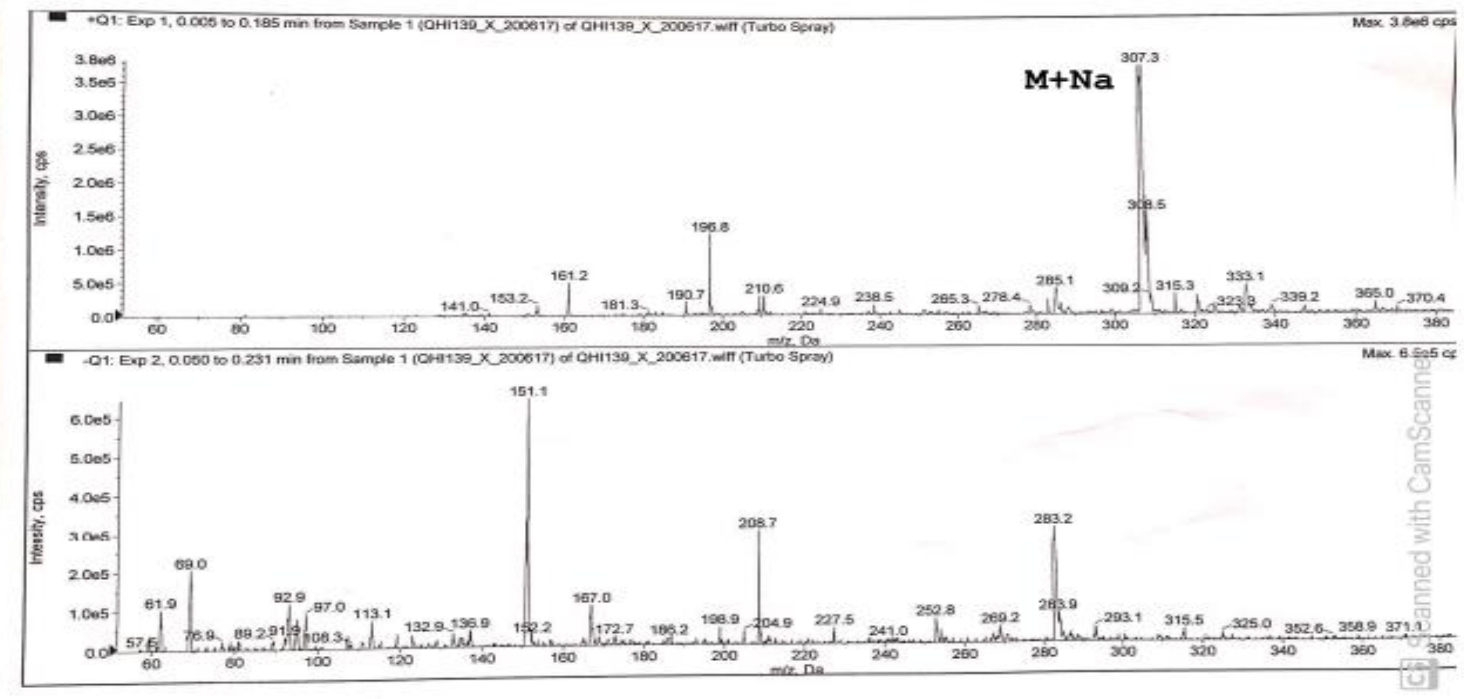

Figure S9: ESIMS spectrum of 4,4'-dimethoxy-2'-hydroxychalcone (3). 


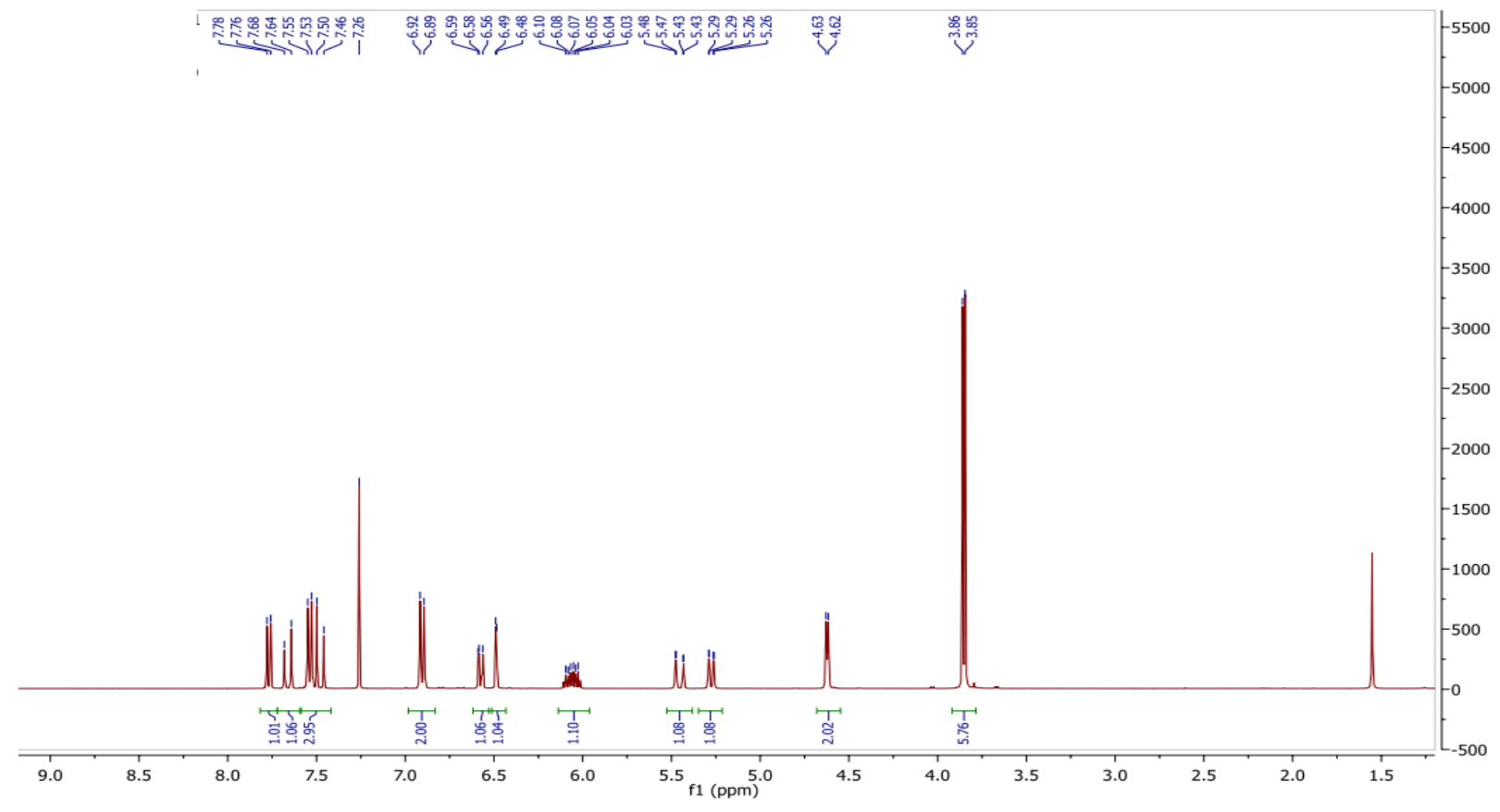

Figure S10: ${ }^{1} \mathrm{H}$ NMR spectrum of 2'-allyloxy-4,4'-dimethoxychalcone (4) $400 \mathrm{MHz}, \mathrm{CDCl}_{3}$ ).

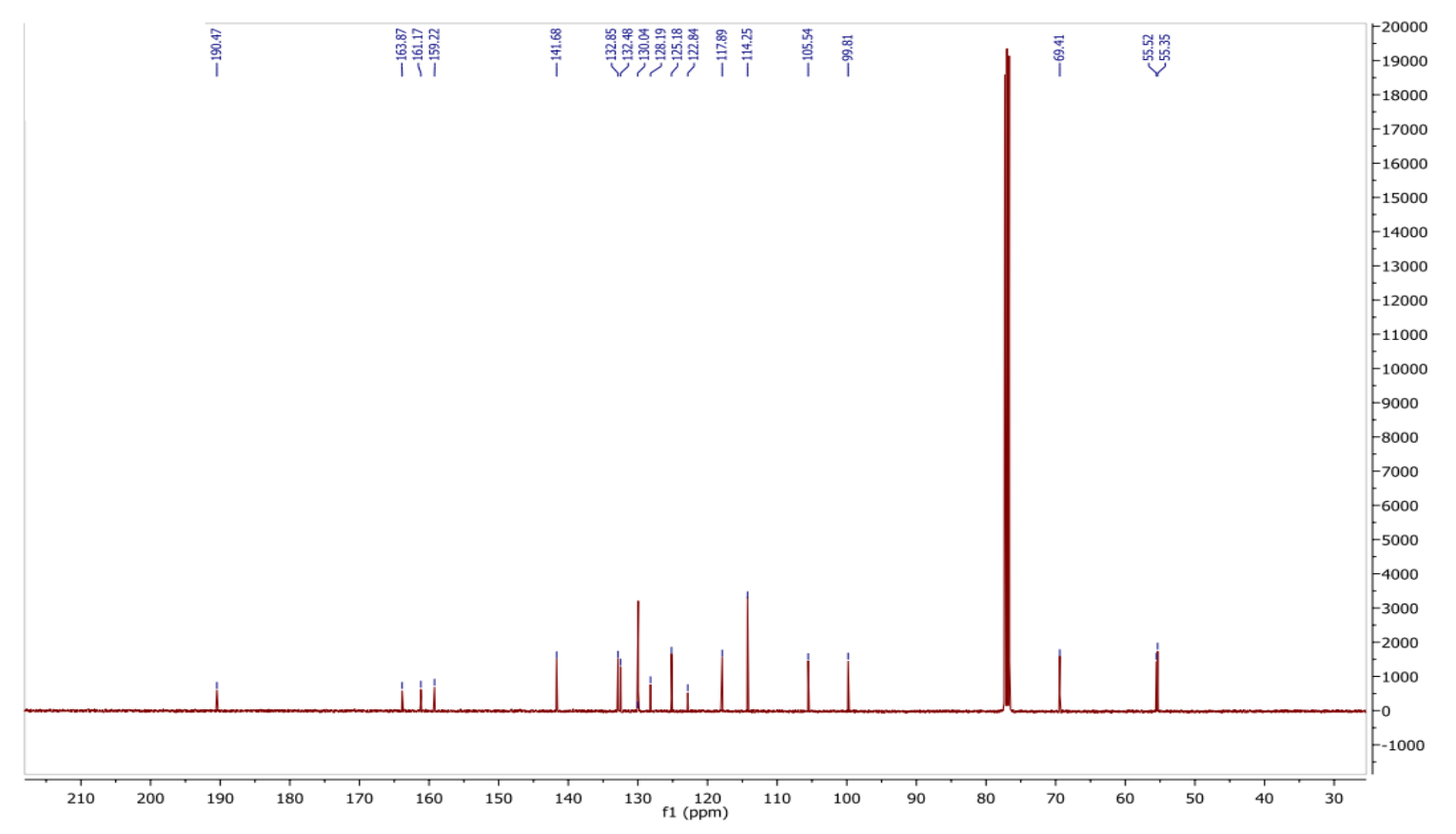

Figure S11: ${ }^{13} \mathrm{C}$ NMR spectrum of 2'-allyloxy-4,4'-dimethoxychalcone (4) $400 \mathrm{MHz}, \mathrm{CDCl}_{3}$ ). 


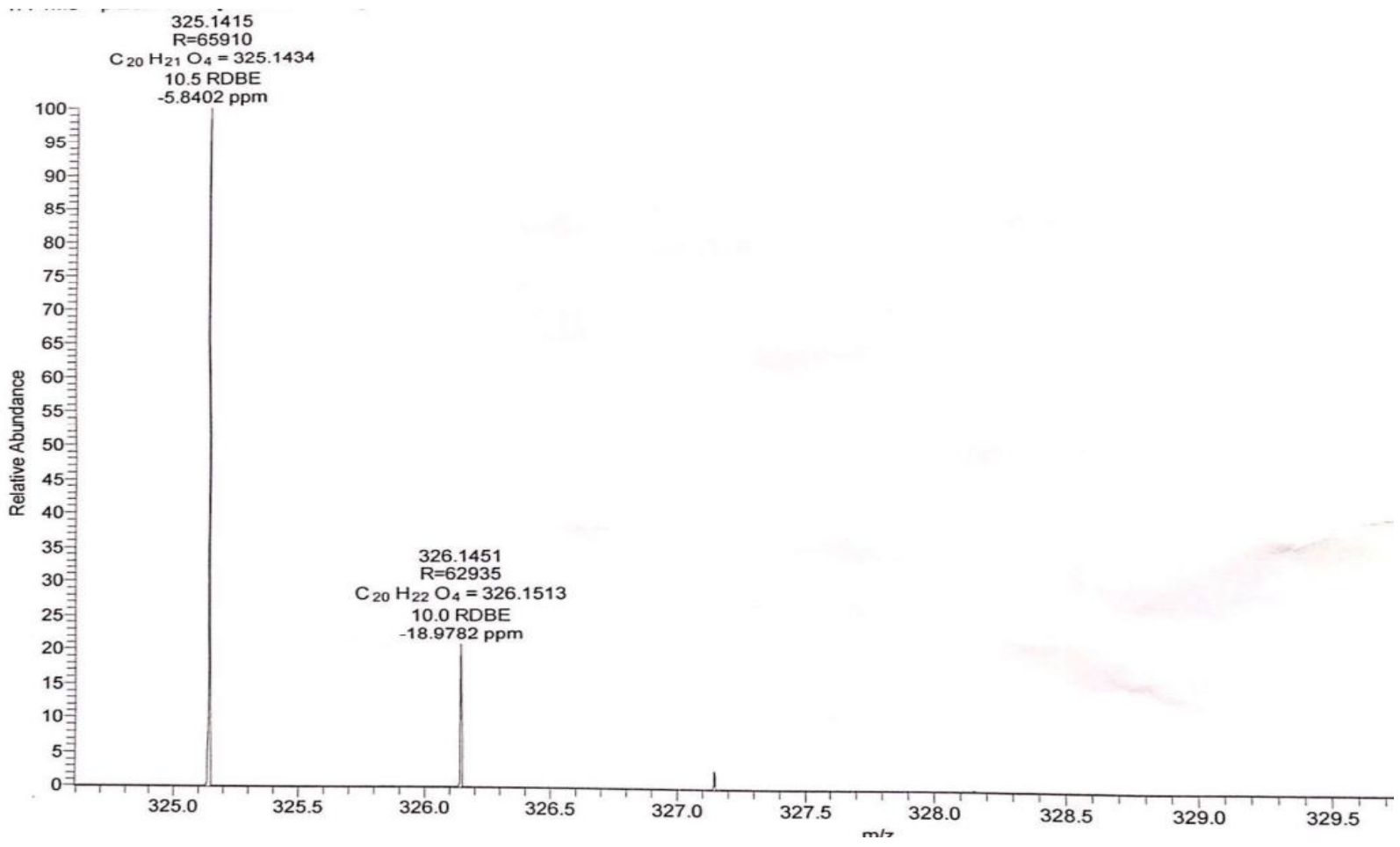

Figure S12: HRESIMS spectrum of 2'-allyloxy-4,4'-dimethoxychalcone (4) 